BMJ Paediatrics Open

\title{
Single-centre prospective observational study on postdelivery room care
}

\author{
Frederike Vivien Hartmann (D) , ${ }^{1}$ Gerd Bauerschmitz, ${ }^{2}$ Helmut Küster ${ }^{1}$
}

To cite: Hartmann FV, Bauerschmitz G, Küster H Single-centre prospective observational study on postdelivery room care. BMJ Paediatrics Open 2020;4:e00602. doi:10.1136/ bmjpo-2019-000602

- Additional material is published online only. To view please visit the journal online (http://dx.doi.org/10.1136/ bmjpo-2019-000602).

Received 1 November 2019 Revised 10 March 2020 Accepted 12 March 2020
Check for updates

(C) Author(s) (or their employer(s)) 2020. Re-use permitted under CC BY-NC. No commercial re-use. See rights and permissions. Published by BMJ.

${ }^{1}$ Neonatology,

Universitätsklinikum Göttingen, Göttingen, Niedersachsen,

Germany

${ }^{2}$ Gynaecology, Universitätsklinikum Göttingen, Göttingen, Niedersachsen, Germany

Correspondence to Helmut Küster; helmut.kuester@ med.uni-goettingen.de

\section{ABSTRACT}

Objectives As quality of care in the delivery room has major impact on outcome of preterm infants, multiple guidelines have been established in recent years. There is, however, little evidence on how to proceed during postdelivery room care, the time of transfer and admission to the neonatal intensive care unit (NICU). The aim of this study was to identify processes taking place during this period with potential impact on outcome.

Study design Prospective observational study.

Setting Single-centre German tertiary NICU.

Patients 40 inborn preterm infants undergoing postdelivery room care.

Main outcome Prevalence of prolonged duration of postdelivery room care, disconnections from the ventilator and positioning of preterm infants.

Results Total duration of postdelivery room care and NICU admission procedures were shorter in infants transferred in a transport incubator compared with using a NICU care station from birth. Extremely low birth weight (ELBW) infants spend $8 \%$ of the time in prone position in contrast to $39 \%$ in non-ELBW. Total duration of disconnection from the ventilator was $50 \mathrm{~s}$ and was ten times longer in infants who had nasal CPAP compared with infants intratracheally intubated. Infants with nCPAP had longer duration of disconnection from the ventilator if body weight was $>1000 \mathrm{~g}$ or if they were transferred in a transport incubator.

Conclusions Multiple parameters like birth weight or type of transport affect neonatal care during the postdelivery room period. Prospective studies are needed to identify and optimise parameters within this period that affect long-term outcome.

\section{INTRODUCTION}

In recent years, the immediate postnatal period has been subject of multiple studies. ${ }^{1-3}$ As a result, many specific standards were established for delivery room (DR) care. ${ }^{4}$ Their implementation resulted in a marked reduction of hypothermia, hypoglycaemia, intraventricular haemorrhage (IVH), retinopathy of prematurity and bronchopulmonary dysplasia.

Unfortunately, there is less data available regarding the care of newborn infants after they leave the DR. Many steps of neonatal care take place within this period that may affect neonatal outcome but prospective clinical studies to analyse the effect of individual measures performed during this time

\section{What is known about the subject?}

The quality of care immediately after birth has major effects on outcome of preterm infants.

- There is less data available regarding the care of these infants after they leave the delivery room.

- Implementing standards has been shown to improve quality and safety of care and therefore may be a valuable tool to improve postdelivery room care.

\section{What this study adds}

Postdelivery room care and neonatal intensive care unit (NICU) admission was shorter in infants transferred in a transport incubator compared with using a NICU care station.

- Total duration of disconnection from the ventilator was 10 times longer in infants who had nCPAP compared with infants intratracheally intubated.

- Time in prone position was longer in infants with nasal CPAP (nCPAP) compared with those intratracheally intubated.

period are still missing. In order to identify potentially outcome determining processes taking place during post-DR care, we closely observed a random sample of preterm infants in a prospective observational study.

One of the focuses was on different duration of time periods identified within the post-DR care because maximising rest periods has been shown to improve developmental outcome of preterm infants. ${ }^{5}$ A second focus was on disconnections from the ventilator because in a study on piglets with acute respiratory distress, those resulted in a time-dependent decruitment of lung regions. ${ }^{6}$ The third focus was on positioning of preterm infants during post-DR care because studies imply that this might be of relevance for preterm infants recovering from respiratory disease. ${ }^{78}$

\section{PATIENTS AND METHODS \\ Patients}

In an exploratory, prospective observational study all inborn premature infants with anticipated need for respiratory support born 
during a predefined period of 24 months in our level IIIb perinatal centre were eligible for inclusion into the study. All data were recorded by one person $(\mathrm{FVH})$ by direct observation.

\section{Definitions}

The observation started after completion of initial care. This was defined as completed once the infant had an intravenous line inserted, a nasogastric tube in place, transcutaneous oxygen saturation was $>80 \%$, respiratory support was secured and the infant was ready for transportation to the neonatal intensive care unit (NICU). The observation ended once the infant was first allowed to rest for a longer period in the NICU.

This observation was divided into four periods: Pretransport, defined as the period after completion of initial care until departure from the DR area; Transport, the period from departure from the DR area until arrival at the NICU; Arrival, from entering the NICU until start of nurses' activity on the infant; Admission, from start of nurses' activity until the end of the observation. In addition, pauses from Handling, defined as nurses' activity on the infant during Admission, were measured.

For analysis, the patient population was divided by birth weight: extremely low birth weight $(E L B W)<1000 \mathrm{~g}$ and not extremely low birth weight (NonELBW) $\geq 1000 \mathrm{~g}$. A local standard operating procedure specifies that all infants with a gestational age below 32 weeks or a birth weight below $1500 \mathrm{~g}$ should not be relocated. The latter means that infants were cared for in the DR in a NICU care station that can also be used for Transport.

\section{Statistics}

Data were analysed using SPSS (V.26.0.0.0), RStudio (V.1.2.5019) and Microsoft Excel (V.16.16.1). Because standard distribution as tested by Q-Q plots was almost always denied, Spearman's rank correlation coefficient, Fisher's exact test, Whitney-Mann-U-test and WilcoxonSigned-rank-test were used as appropriate. The marginated model F1 LD F1 using R package npar LD for nonparametric analysis was used as appropriate. ${ }^{9} 10$ Bonferroni correction for multiple testing was applied. Significance was set at $\mathrm{p}<0.05$.

\section{Patient and public involvement statement}

Medical staff of neonatology were involved prior to observation by suggesting the focus on certain aspects of post-DR care from their work experience.

\section{RESULTS}

\section{Patient characteristics}

Between 1 June 2017 and 31 May 2019, a total of 139 patients were eligible for inclusion into the study. Finally, $40(29 \%)$ infants underwent observation as outlined above due to the availability of the observer (online supplementary figure 2). Median gestational age was 31 weeks and median birth weight $1645 \mathrm{~g}$, all except two

\begin{tabular}{|c|c|c|c|c|}
\hline & $\begin{array}{l}\text { All } \\
(n=40)\end{array}$ & $\begin{array}{l}\text { ELBW } \\
(n=13)\end{array}$ & $\begin{array}{l}\text { Non-ELBW } \\
(n=27)\end{array}$ & $P$ value \\
\hline $\begin{array}{l}\text { Gestational age } \\
\text { (weeks) }\end{array}$ & $\begin{array}{l}31 \\
(27-34)\end{array}$ & $\begin{array}{l}26 \\
(25-26)\end{array}$ & $\begin{array}{l}34 \\
(31-35)\end{array}$ & $0.78^{*}$ \\
\hline Birth weight (g) & $\begin{array}{l}1645 \\
(794-2258)\end{array}$ & $\begin{array}{l}720 \\
(580-775)\end{array}$ & $\begin{array}{l}1960 \\
(1645-2490)\end{array}$ & $0.81^{*}$ \\
\hline Female/male (n) & $19 / 21$ & $6 / 7$ & $13 / 14$ & $0.99 \dagger$ \\
\hline $\begin{array}{l}\text { Any respiratory } \\
\text { support (n) }\end{array}$ & 34 & 13 & 21 & $0.15 \dagger$ \\
\hline $\operatorname{nCPAP}(n)$ & 26 & 7 & 19 & $0.50 \dagger$ \\
\hline $\begin{array}{l}\text { Intratracheal } \\
\text { ventilation (n) }\end{array}$ & 8 & 6 & 2 & $0.01 \dagger$ \\
\hline
\end{tabular}

Data given are median and (IQR) for basic characteristics of patients and their type of ventilation.

*Spearman's rank correlation coefficient (r).

†Fisher Exact test.

ELBW, extremely low birth weight.

were delivered by Caesarean section (table 1 ). Of the 40 infants, 24 were transported in an NICU care station, the remaining 16 were transported in an transport incubator and consequently needed two relocations. Infants with $E L B W$ were less often transferred by transport incubator and therefore less often relocated $(\mathrm{p}=0.005$, Fisher Exact test). Most infants with respiratory support were not relocated for Transport ( $\mathrm{p}=0.002$, Fisher Exact test). Of the 34 infants with respiratory support, eight were intratracheally intubated, 6/8 infants were $E L B W$. ELBW infants were more often intratracheally intubated than NonELBW infants $(\mathrm{p}=0.01$, Fisher Exact test).

\section{Time periods}

The median total duration from end of DR care until the infants were allowed to rest for a longer time in the NICU was $62 \mathrm{~min}$ (table 2). The duration of the four periods

Table 2 Time duration of the four intervals in relation to the birth weight

\begin{tabular}{lllll}
\hline & $\begin{array}{l}\text { All } \\
(\mathbf{n = 4 0 )}\end{array}$ & $\begin{array}{l}\text { ELBW } \\
(\mathbf{n = 1 3})\end{array}$ & $\begin{array}{l}\text { Non-ELBW } \\
(\mathbf{n = 2 7})\end{array}$ & $\begin{array}{l}\mathbf{P} \\
\text { value* } \boldsymbol{~}\end{array}$ \\
\hline $\begin{array}{l}\text { Total } \\
\text { (min) }\end{array}$ & $\begin{array}{l}62 \\
(53-69)\end{array}$ & $\begin{array}{l}69 \\
(56-85)\end{array}$ & $\begin{array}{l}60 \\
(53-64)\end{array}$ & 0.045 \\
\hline $\begin{array}{l}\text { Pretransport } \\
\text { (min) }\end{array}$ & 18 & 16 & 19 & 0.285 \\
\hline $\begin{array}{l}\text { Transport } \\
\text { (min) }\end{array}$ & 7 & 9 & 6 & 0.016 \\
\hline $\begin{array}{l}\text { Arrival } \\
\text { (min) }\end{array}$ & $(6-9)$ & $(6-10)$ & $(5-8)$ & \\
\hline $\begin{array}{l}\text { Admission } \\
\text { (min) }\end{array}$ & $(5-11)$ & $(4-13)$ & $(5-11)$ & 0.63 \\
\hline
\end{tabular}

Data are given as median and (IQR).

*Mann-Whitney-U-test looking for the influence of birth weight within each period of the post-DR care.

†Significance was set to $p<0.0125$ on the basis of Bonferroni correction.

ELBW, extremely low birth weight. 
of the post-DR care differed in their duration depending on birth weight, $E L B W$ or NonELBW (p=0.000, F1 LD F1 Model, npar LD package R). But there was no influence of the birth weight on the duration within any of the periods when results were corrected for multiple testing (Whitney-Mann-U-test with Bonferroni correction). Still there was a trend implying that time periods lasted longer if the infants were $E L B W$.

When testing within each of the four periods of the post-DR care for an impact of the type of transport, the Admission as well as the total time was shorter if a transport incubator was used for Transport ( $\mathrm{p}=0.001, \mathrm{p}=0.000$, Whitney-Mann-U-test) (online supplementary table 4). The four periods varied in their duration when compared with one another, for example, the Transport was shorter than the Pretransport within the group of ELBW infants $(\mathrm{p}=0.006$, Wilcoxon-Signed-rank test). Because this is not of clinical importance, no details are given.

Extended pauses from Handling the infant during Admission were observed if they were not relocated for Transport ( $\mathrm{p}=0.004$, Whitney-Mann-U-test with Bonferroni correction). Waiting times during arrival at the NICU did not differ between patient groups. Within these time periods, different activities were carried out. In all but one infant, ECG and blood pressure were first taken during Admission. Repeated temperature measurements by thermometer were always recorded before our observation period in the DR and during Admission. Continuous temperature by skin probe was taken in half of the infants before start of observation and in $87 \%$ during Admission. A continuous skin probe was more often established already during Pretransport if no relocation to a transport incubator occurred ( $\mathrm{p}<0.01$, Fisher Exact test). Body weight was taken before start of observation in only one infant. In $15 \%$ of the infants, weight was measured during Pretransport and in $82 \%$ during Admission. Head circumference and length were measured only once before start of observation, in 5\% during Pretransport and in $74 \%$ during Admission.

\section{Respiratory support}

The median duration of disconnection from the ventilator was $50 \mathrm{~s}$. Looking only at infants who received any respiratory support, infants with nCPAP had longer duration of disconnection in comparison to infants who were intratracheally intubated ( $\mathrm{p}=0.000$, Whitney-MannU-test) (table 3). Of the 26 infants with nCPAP, four initially had a binasal mask and 22 a single-nasal interface that was changed during Admission in all but one infant to a binasal mask (figure 1). Change of interface lasted $3.1 \mathrm{~min}$ in median while the time of disconnection itself was $34 \mathrm{~s}$. Within the group of infants supported by nCPAP, longer duration of disconnection occurred if they were NonELBW or a transport incubator was used for Transport ( $\mathrm{p}=0.01, \mathrm{p}<0.01$, Whitney-Mann-U-test $)$. No difference in the duration of disconnection could be shown between the initial use of either a singlenasal or binasal nCPAP interface (median $102 \mathrm{~s}$ vs $90 \mathrm{~s}$ ).

\begin{tabular}{|c|c|c|c|c|}
\hline & $\begin{array}{l}\text { Infants with } \\
\text { respiratory } \\
\text { support } \\
(\mathrm{n}=34)\end{array}$ & $\begin{array}{l}\text { ELBW } \\
(n=13)\end{array}$ & $\begin{array}{l}\text { Non-ELBW } \\
(n=21)\end{array}$ & P value $^{*} \dagger$ \\
\hline $\begin{array}{l}\text { Intubation } \\
\text { (s) }\end{array}$ & $\begin{array}{l}12 \\
(7-21)\end{array}$ & $\begin{array}{l}10 \\
(6-19)\end{array}$ & $\begin{array}{l}17 \\
(14-20)\end{array}$ & 0.310 \\
\hline $\begin{array}{l}\text { nCPAP } \\
\text { (s) }\end{array}$ & $\begin{array}{l}104 \\
(48-161)\end{array}$ & $\begin{array}{l}23 \\
(20-68)\end{array}$ & $\begin{array}{l}125 \\
(67-157)\end{array}$ & 0.010 \\
\hline P value†‡ & 0.000 & 0.022 & 0.023 & \\
\hline
\end{tabular}

Data given are median and (IQR) for infants who needed respiratory support.

*Mann-Whitney-U-test looking at the influence of birth weight within one respiratory support strategy on the duration of disconnection.

†Significance was set to $p<0.0125$ on the basis of Bonferroni correction.

$\ddagger$ Mann-Whitney-U-test looking at the influence of a certain respiratory support strategy on the duration of disconnection. ELBW, extremely low birth weight.

Handling during Admission was shorter within the group with binasal nCPAP (12 min) compared with the group receiving a single-nasal interface $(22 \mathrm{~min}) \quad(\mathrm{p}=0.02$, Whitney-Mann-U-test). Of the 40 infants, three received surfactant during initial care, another 15 infants later during Admission to the NICU. Of the 15, nine initially had nCPAP and six were intratracheally intubated, seven were ELBW. No difference was found between the length of time after birth until surfactant was applied and the mode of respiratory support or the birth weight.

\section{Positioning of the infant}

Infants spend $70 \%$ of the total time in supine position (online supplementary table 5). The percentage of time an infant was in prone or supine position was not different between the groups during any of the four periods of the post-DR care. $E L B W$ infants spent $8 \%$ of time in prone position compared to $39 \%$ of the NonELBW. Intratracheally intubated infants spent more time in a supine position $(100 \%)$ than infants receiving nCPAP $(50 \%)$ ( $\mathrm{p}=0.004$, Whitney-Mann-U-test).

\section{DISCUSSION}

The First Golden Hour of Life is known to be a critical period in the care of preterm infants as many outcomedetermining procedures are taking place. ${ }^{11}$ This prospective observational study gives a first closer insight in potentially outcome determining variables: duration of post-DR care, duration of disconnection from the ventilator and positioning of the infant. It also demonstrated that even within a single-centre, post-DR care procedures vary depending on birth weight and type of transport. Due to potential impacts of interventions taking place during post-DR care, we suggest this time period to be called Second Golden Hour of Life. 


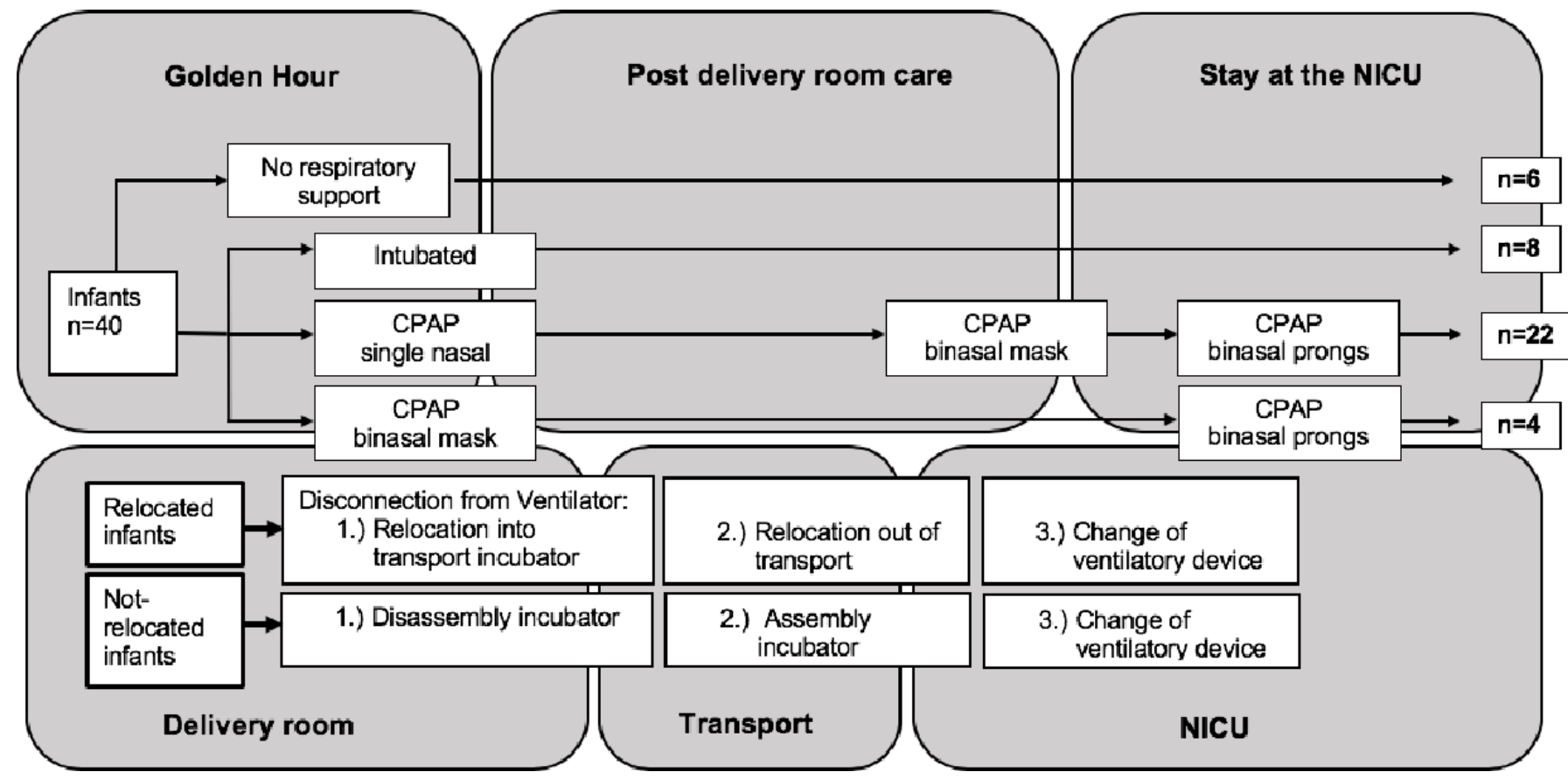

Figure 1 Strategies of respiratory support. Four different strategies of respiratory support are displayed as performed at the University Medical Centre Göttingen. Settings with potential disconnection from the ventilator are shown depending on type of transport. Relocated, infants relocated for transport. Not-relocated, infants not relocated for transport. NICU, neonatal intensive care unit.

This study shows a trend that implies post-DR care to last longer if the infant was $E L B W$. This allows to assume that a more cautious handling in infants with $E L B W$ resulted in a prolonged duration of post-DR care. It could be shown that post-DR care was shorter in infants that were relocated for Transport into a transport incubator. However, this had to put up with infants being disconnected from the ventilator for a longer time if they are relocated for Transport. Including this change of interface, a median of six interventions were observed during the 23 min of Admission. On the other hand, no intervention happened on the infant within a fifth of the Admission. Studies suggest that developmental care routines such as maximising rest periods improve developmental outcome and support the autonomic stability and selfregulation abilities of preterm infants. ${ }^{5}$ A solution may be to postpone non-mandatory interventions such as measurement of length and head circumference and to perform necessary interventions as quickly as possible without any interruptions.

Experiments in piglets with acute respiratory distress syndrome have shown that derecruitment of the lung is observed within $3 \mathrm{~s}$ after reduction of airway pressure. ${ }^{6}$ In our study, an in comparison fourfold duration of disconnection from the ventilator was observed in the intratracheally ventilated infants. Such an extended duration of disconnection may lead to an increased risk of atelectasis and may thereby increase the risk for clinically relevant acute respiratory distress syndrome. When compared with intratracheally ventilated $E L B W$ infants, disconnections were 10 times longer if the infants were NonELBW or on nCPAP. The reason may be the staffs' assumption that these infants are less PEEP dependent. But the resulting formation of atelectasis due to prolonged disconnection from the ventilator may not be clinically apparent immediately.

In order to minimise the duration of disconnection from the ventilator, two different approaches are conceivable. First, the type of transport had an impact as relocation of infants between transport incubator and NICU care station resulted in twice the duration of disconnection when compared with transport with a NICU care station in which the infants did not have to be relocated. In the protocol of developmental care, McLendon et al emphasised to perform DR care of very low birth weight infants in a NICU care station to eliminate the need for relocation. When combined with other measures like neutral head positioning, this regimen has been shown to result in a significant decrease in the rate of IVH. ${ }^{12} 13$

The second approach to minimise the duration of disconnection may be to supply the infant with binasal nCPAP from the beginning instead of initially using a single nasal interface and switching to a binasal mask later. Disconnection could be reduced by one third in infants receiving nCPAP if the nCPAP interface was not changed during Admission. Moreover, duration of Pretransport was not prolonged and Handling was shortened in the group of infants with a binasal nCPAP interface from the beginning. In addition to a reduction of disconnection, binasal nCPAP has been shown to be more effective in reducing the rate of reintubation compared with single prongs. ${ }^{14}$

For years prone position has been standard in neonatal care as it has been shown to improve respiratory effort, lung volume and to reduce rate of apnoea's in general. ${ }^{15}$ But for preterm infants mechanically ventilated, no evidence was found that a particular position may be 
beneficial. ${ }^{16}$ Small studies imply that short-term prone positioning decreases cardiac output and skin blood flow in those infants receiving non-invasive respiratory support. ${ }^{17}$ As nasal prongs dislocate more often in prone position, ${ }^{18}$ there is lack of evidence of which position is the most beneficial in delivering adequate non-invasive respiratory support.

Unexpectedly, in our study, infants with respiratory support spent almost three-quarters of the total observation in supine position. Moreover, intratracheally ventilated infants spent more time in supine position when compared with infants with nCPAP and ELBW infants more (92\%) than NonELBW infants (61\%). Again, a more cautious approach of the caregivers might be the reason for the overwhelming use of supine position and may have its reason in the aim to prevent two additional changes of position in the most vulnerable population.

The choice of incubator type did not affect positioning of the infants. Leaving all infants in the same position during delivery and post-DR care may reduce the stress of repositioning and may be in line with experimental results. ${ }^{19}$ Infants receiving any respiratory support reached their physiological peak in lung function twohour after repositioning independent from their actual position, while spontaneously breathing infants were less affected by relocation. Therefore, prospective studies are needed to evaluate if and when repositioning of an infant may be of advantage.

\section{Limitations of the study}

This observational study for the first time prospectively recorded and analysed time segments and processes during post-DR care. Being without predecessor, it captured in detail all events and their timing in a limited number of patients. This study, however, may serve as a model for future multicentre studies on post-DR care. Such studies may focus on which position of the infant would be beneficial to reduce the need for subsequent intratracheal intubation. Larger trials could analyse if changing the nCPAP interface for transport has any lasting effect. Such studies should also include results on long-term outcome. Due to organisational circumstances, this study looked almost exclusively at preterm infants born by Caesarean section, results may differ if spontaneously born infants are included as well. And results of this study might have been different if the DR would have been wall to wall to the NICU as suggested by current guidelines. ${ }^{20}$

\section{CONCLUSION}

This first observational study on the management during post-DR care shows that multiple parameters like birth weight or type of transport affect timing and duration of transfer from the DR to the NICU. Prolonged disconnection from the ventilator and positioning of infants was consistent but lacks a scientific basis. Prospective studies are needed to identify and optimise parameters within this Second Golden Hour of Life that effect long-term outcome.

Acknowledgements We are grateful to all nurses and physicians for their assistance and the Institute of Medical Statistics Göttingen for statistical advice.

Contributors FVH collected the data, performed calculations and drafted the manuscript with support from HK and GB. GB was involved in designing the study and assisted in data analysis. HK devised the study and main conceptual ideas. HK and GB reviewed the manuscript. All authors critically discussed results and approved the final manuscript.

Funding The authors have not declared a specific grant for this research from any funding agency in the public, commercial or not-for-profit sectors.

Competing interests None declared.

Patient consent for publication Not required.

Ethics approval The study was approved by the local ethical committee of the University Medical Centre Göttingen, Germany.

Provenance and peer review Not commissioned; externally peer reviewed.

Data availability statement Data are available upon reasonable request. A table with all data is available to interested users for further corporate analysis.

Open access This is an open access article distributed in accordance with the Creative Commons Attribution Non Commercial (CC BY-NC 4.0) license, which permits others to distribute, remix, adapt, build upon this work non-commercially, and license their derivative works on different terms, provided the original work is properly cited, appropriate credit is given, any changes made indicated, and the use is non-commercial. See: http://creativecommons.org/licenses/by-nc/4.0/.

ORCID iD

Frederike Vivien Hartmann http://orcid.org/0000-0002-5892-4076

\section{REFERENCES}

1 Perlman JM, Wyllie J, Kattwinkel J, et al. Part 7: neonatal resuscitation: 2015 international consensus on cardiopulmonary resuscitation and emergency cardiovascular care science with treatment recommendations. Circulation 2015;132:S204-41.

2 Edwards EM, Soll RF, Ferrelli K, et al. Identifying improvements for delivery room resuscitation management: results from a multicenter safety audit. Matern Health Neonatol Perinatol 2015;1:2.

3 Reynolds RD, Pilcher J, Ring A, et al. The golden hour: care of the LBW infant during the first hour of life one unit's experience. Neonatal Netw 2009;28:211-9. quiz 55-8.

4 Wyckoff MH, Aziz K, Escobedo MB, et al. Part 13: neonatal resuscitation: 2015 American heart association guidelines update for cardiopulmonary resuscitation and emergency cardiovascular care. Circulation 2015;132:S543-60.

5 Cabral LA, Velloso M. Comparing the effects of minimal handling protocols on the physiological parameters of preterm infants receiving exogenous surfactant therapy. Braz $J$ Phys Ther 2014;18:152-64.

6 Boehme S, Bentley AH, Hartmann EK, et al. Influence of inspiration to expiration ratio on cyclic recruitment and derecruitment of atelectasis in a saline lavage model of acute respiratory distress syndrome. Crit Care Med 2015;43:e65-74.

7 Maynard V, Bignall S, Kitchen S. Effect of positioning on respiratory synchrony in non-ventilated pre-term infants. Physiother Res Int 2000;5:96-110

8 Wolfson MR, Greenspan JS, Deoras KS, et al. Effect of position on the mechanical interaction between the rib cage and abdomen in preterm infants. J Appl Physiol 1992;72:1032-8.

9 Kimihiro Noguchi YG, Brunner E, Konietschke F. nparLD- an R software package for the nonparametric analysis of longitudinal data factorial experiments. Journal of Statistical Software 2012;50.

10 Brunner E, Puri ML. Nonparametric methods in factorial designs. Statistical Papers 2001;42:1-52.

11 Sharma D. Golden hour of neonatal life: need of the hour. Matern Health Neonatol Perinatol 2017;3:16.

12 McLendon D, Check J, Carteaux P, et al. Implementation of potentially better practices for the prevention of brain hemorrhage and ischemic brain injury in very low birth weight infants. Pediatrics 2003;111:e497-503.

13 Kochan M, Leonardi B, Firestine A, et al. Elevated midline head positioning of extremely low birth weight infants: effects on 
cardiopulmonary function and the incidence of periventricularintraventricular hemorrhage. J Perinatol 2019;39:54-62.

14 Dargaville PA, Gerber A, Johansson S, et al. Incidence and outcome of CPAP failure in preterm infants. Pediatrics 2016;138:e20153985.

15 Poets CF, Bodman Avon. [Sleeping position for preterm infants]. $Z$ Geburtshilfe Neonatol 2008;212:27-9.

16 Rivas-Fernandez M, Roqué I Figuls M, Diez-Izquierdo A, et al. Infant position in neonates receiving mechanical ventilation. Cochrane Database Syst Rev 2016;11:Cd003668.

17 Ma M, Noori S, Maarek J-M, et al. Prone positioning decreases cardiac output and increases systemic vascular resistance in neonates. J Perinatol 2015;35:424-7.
18 Brunherotti MAA, Martinez FE. [Influence of body position on the displacement of nasal prongs in preterm newborns receiving continuous positive airway pressure]. Rev Paul Pediatr 2015;33:281-6.

19 Hough J, Trojman A, Schibler A. Effect of time and body position on ventilation in premature infants. Pediatr Res 2016;80:499-504.

20 Hecken P. Tragende Gründe zum Beschluss des Gemeinsamen Bundesausschusses über eine Änderung der QualitätssicherungsRichtlinie Früh- und Reifgeborene: Einführung der $\S \S 8,9$ sowie Änderungen in den Ziffern I.2.2 und II.2.2 der Anlage 2. Gemeinsamer Bundesausschuss gemäß § 91 SGB V. 18. Mai, 2017. Available: https://www.g-ba.de/downloads/40-268-4480/2017-0615_QFR-RL_Erstfassung-Anlage-5_TrG.pdf [Accessed 10 Aug 2019]. 